\title{
The initiation of simulation training at a large community hospital
}

\author{
Cornelia R. Graves, MD, ${ }^{1}$ Geoffrey H. Smallwood, MD, ${ }^{1}$ Phillip L. Bressman, MD, ${ }^{1}$ \\ Douglas H. Brown, MD, ${ }^{1}$ John E. VanHooydonk, MD, ${ }^{1}$ Stephen M. Staggs, MD, ${ }^{1}$ Henry \\ Clay Newsome, MD, ${ }^{1}$ Tristin A. Casteel, MBA, ${ }^{2}$ Jessica C. Wells, $\mathrm{MS}^{2}$
}

Key words: community hospital, simulation training

\begin{abstract}
OBJECTIVE: Since the 1990's, simulation has been used to maintain task-oriented and behavioral skills in obstetrics and gynecology. Data on its effectiveness is still limited. The purpose of this study is to describe our experience in implementing simulation exercises at a large, private hospital.
\end{abstract}

STUDY DESIGN: After reviewing the malpractice claims and maternal mortality impact of shoulder dystocia and postpartum hemorrhage, and the potential for a positive impact on patient safety through simulation training, shoulder dystocia and postpartum hemorrhage were selected as the initial focus of a new simulation training program for attending obstetrical physicians at a large, private, urban hospital. Upon obtaining approval from the institution, the Simulation Working Group developed an obstetrical simulation program emphasizing the management of shoulder dystocia and postpartum hemorrhage. Physicians who participate in deliveries at the institution were required to review a web-based educational program prior to the simulation exercise. Pre and post test questions were developed to assess the effectiveness of the information provided. The data were analyzed using Chi-Square testing with a p-value of $<0.05$ considered to be statistically significant.

RESULTS: Data were collected from 71 respondents. The average number of years since residency was 17 years. For shoulder dystocia, the average pre test score was $79.01 \%$ and the average post test score was $94.37 \%$ (increase of $19.43 \% ; p<0.05$ ). For postpartum hemorrhage the average pre test score was $87.46 \%$ and the average post test score was $94.37 \%$ (increase of $7.89 \% ; p-N S$ ). At three month follow up, $20 \%$ of respondents indicated they had implemented a practice change in managing a shoulder dystocia or postpartum hemorrhage case that would not have been implemented prior to participating in the training. $85.2 \%$ of respondents stated they were likely to attend another CME activity involving simulation. $92.6 \%$ of respondents felt that compared to other educational modalities, simulation offered the best value for time spent.

CONCLUSION: Implementation of a simulation program in a non-academic institution is feasible and resulted in improved didactic knowledge with a satisfactory learning environment for experienced providers.

${ }^{1}$ Baptist Hospital, Nashville, TN

${ }^{2}$ Saint Thomas Health, Nashville, TN

INTRODUCTION

Since the 1990's, simulation-based clinical training has been expanded to address events in which urgent, accurate and cohesive team functioning is important. ${ }^{1}$ The use of simulation training in obstetrical training has been developing rapidly over the last few years, as studies have explored the use

Please cite this paper as: Graves CR, Smallwood GH, Bressman PL, Brown, DH, VanHooydonk JE, Staggs SM, Newsome HC, Casteel TA, Wells JC. The initiation of simulation training at a large community hospital. Proc Obstet Gynecol. 2012 May 2(3):Article 9 [ 12 p.]. Available from: http://ir.uiowa.edu/pog/. Free full text article.

Corresponding author: Tristin A. Casteel, MBA, Saint Thomas Health, Nashville, TN, tristin.casteel@stthomas.org

This is an Open Access article distributed under the terms of the Creative Commons Attribution 3.0 Unported License (http://creativecommons.org/licenses/by/3.0), which permits unrestricted use, distribution, and reproduction in any medium, provided the original work is properly cited. 
of simulation as a training tool to improve technical skills of obstetricians. Some studies have demonstrated an improvement in clinical outcomes with the use of simulation technique to train labor and delivery units on the management of shoulder dystocia. ${ }^{2}$ However, there are very few studies demonstrating the feasibility of simulation training in non-academic centers.

In 1996, the CDC reported 7.6 maternal deaths per 100,000 live births. ${ }^{3}$ This number doubled to 13.3 in 2006, accentuating the need for a dedication to improving the care of mother and baby. ${ }^{4}$ Postpartum hemorrhage has been recognized as a leading cause of significant maternal morbidity and mortality. Data suggest that failure to recognize and delay in treatment increase the risk for a poor outcome. ${ }^{5}$ Shoulder dystocia may complicate up to $2 \%$ of all vaginal deliveries and may be associated with long term complications due to brachial plexus injuries, clavicular fracture, hypoxic brain injury, maternal lacerations and neonatal death. ${ }^{6}$

The purpose of this study is to describe our experience in implementing a simulation program initially focused on clinical management of shoulder dystocia and postpartum hemorrhage for attending physicians at a large, private, urban hospital.

\section{MATERIALS AND METHODS}

The institution and leaders in the Department of Obstetrics and Gynecology (OB/GYN) initiated the development and implementation of a simulation training program as a mechanism to promote and sustain the highest level of patient safety. While the institution had implemented a Critical Event Team Training (CETT) program utilizing simulation for nursing staff three years prior, the Chief of the Department of Obstetrics and Gynecology in 2010 championed the idea to implement a simulation training program focused on the clinical skills and teamwork principles essential for physicians managing obstetrical emergencies. To secure financial and structural support for such a program, the Chief of OB/GYN presented the idea to hospital executives. As support for his proposal, the Chief referenced the Safe Care Initiative launched by the hospital in 2007. The Safe Care Initiative was intended to transform the culture to that of a high-reliability organization, identify high risk behavior, analyze precursor events and near misses, and deploy human error prevention tools to improve patient care. All medical, clinical, and non-clinical staff was mandated to complete the required educational components of the Safe Care Initiative. The Chief identified simulation training as a mechanism for continuing the Safe Care Initiative in obstetrics, and showed the alignment between the proposed obstetrical simulation program and the institution's guiding principles surrounding patient safety. The hospital executives realized that simulation training could be an essential and sustaining component of a culture focused on safe patient care, and agreed to provide full funding and staff support through the Department of Continuing Medical Education (CME) to develop and implement the on-going Obstetrical Emergency Simulation Training Program (Program) for attending physicians. 
With the support of the institution, OB/GYN Department (Department) leaders proposed that completion of the Program be required as part of recredentialing for obstetrical privileges. With an acute awareness for the potential physician resistance that could arise from such a requirement, the proposal was presented to the Department for majority vote. In addition, the proposal included the following caveats:

1. The Program leadership would pursue malpractice premium credit from the insurance carriers covering the majority of the Department members,

2. The Program would replace the fetal monitoring course previously required as an educational component for credentialing or re-credentialing, and

3. Program Faculty members would be nominated by their peers and approved by the hospital's Obstetrics Executive Committee.

The Department voted and unanimously approved the proposal at the first quarterly department meeting in 2010 .

After nomination and approval, six board-certified OB/GYN Generalists and one board certified Maternal Fetal Medicine Specialist committed to joining the Program Faculty (Faculty). Each with more than 20 years of clinical experience, the Faculty was made up of the Department Chief who served as Course Director, the hospital's Director of Perinatal Services, two full-time staff laborists, and three general obstetricians. Each Faculty member committed to the Program based on a pre-determined honorarium schedule that outlined the amount to be paid for content development and moderating hands-on sessions. The hospital's CME Director oversaw and guided the project, and provided updates to hospital leaders. A coordinator from the CME Department was assigned as the Program Coordinator, and managed all administrative, logistical and scheduling functions for the Program. The Program Coordinator worked with the Faculty to identify common availability for planning meetings, as well as general day and time availability for moderating hands-on sessions. Planning meetings were scheduled outside of clinic hours, and hands-on sessions were scheduled on various days of the week and at various times during the day. Faculty members made themselves available to moderate hands-on sessions before and after clinic hours, during time designated for administrative duties, and during unscheduled surgery time slots. The Program Coordinator contacted the participants individually to schedule them for an available hands-on session.

Recognizing that premium credit could be an effective incentive for the Program, the Department Chief had previously presented a general proposal of an obstetrical simulation course to Risk Management Representatives from local malpractice insurance carriers to gauge their initial interest. The hospital's focus on patient safety and reputation for excellence in obstetrics, coupled with current literature surrounding potential benefits of simulation training, allowed the proposal to earn interest from the Representatives. Following the Department approval of the mandatory Program and the selection of Faculty, the Department Chief and CME Director engaged the Representatives to confirm their interest and identify their 
requirements for assigning premium credit to the course. The Carriers required a review of the final didactic materials, and observation of a simulation exercise demonstration before giving final approval for premium credit.

Educational materials and simulation exercises were developed by the Faculty over the course of four months. The Faculty and Director of CME determined that the Program would consist of a didactic component that would be the prerequisite to the handson simulation session. The didactic component of the program was delivered in a web-based format that could be accessed 24 hours per day and seven days per week. This delivery method was selected based on the flexibility for participants to view the didactic material at their convenience from any computer with an Internet connection. The CME Department had an existing web-based platform that was modified to support the Program's shoulder dystocia and postpartum hemorrhage didactic modules. Each module consisted of a pre test, a slideshow with voiceover script read by the Course Director, and a post test. The Faculty reviewed current literature and guidelines to outline the evidencebased management strategies that were presented in the modules. The Faculty then developed hands-on simulation exercises that required the use of the evidence-based management strategies outlined in the didactic modules. The exercises were varied to include typical and atypical patients presenting with shoulder dystocia and postpartum hemorrhage. The Faculty tested the scenarios by conducting train-the-trainer sessions prior to launching the Program. The train-the-trainer sessions gave each faculty member an opportunity to play the role of a moderator and a participant.

To foster a team-based environment and approach to patient care, staff nurses participated in the hands-on simulation exercises. Nurses played the role they would play in an actual delivery, and participants were encouraged to communicate with them accordingly. The Program Coordinator collaborated with the Labor and Delivery Department Nurse Managers to recruit nursing participants. Staff nurses signed up to participate in hands-on sessions during their days off, and were compensated at their regular hourly rate for their time spent in the sessions. In addition, nurses received points for their professional development incentive program for each session in which they participated.

At the time of the hands-on simulation session, the participant was guided through a series of events with a checklist developed to reinforce the materials emphasized in the didactic setting (see Figures 1 and 2). In addition to using the checklists as a guide for training, the Faculty also utilized the results from participants' didactic pre and post tests to target individual education needs in the simulation setting. Following each scenario, the physician participant, nurse helping with the session, and the Faculty moderator participated in debriefing sessions to reinforce team communication techniques. The Faculty members each had varying levels of experience and training in team communication and debriefing; therefore, the group reviewed current literature to identify key principles to convey during the hands-on sessions. Principles for team 


\begin{tabular}{|c|c|c|c|}
\hline \multicolumn{4}{|c|}{ Obstetrical Simulation: Shoulder Dystocia (SD) Onsite Checklist } \\
\hline \multicolumn{3}{|l|}{ Student Name: } & \multirow[t]{2}{*}{ Date: } \\
\hline Instructor Name: & & & \\
\hline Clinical Skills & Done & Not Done & Comments \\
\hline \multicolumn{4}{|l|}{ Describes worst SD case } \\
\hline \multicolumn{4}{|l|}{$\begin{array}{l}\text { Identifies risk factors for SD: } \\
\text { history of a previous macrosomic infant, history } \\
\text { of a previous delivery complicated by SD, fetal } \\
\text { macrosomia in the current pregnancy, diabetes } \\
\text { mellitus in the current pregnancy }\end{array}$} \\
\hline \multicolumn{4}{|l|}{ Recognizes SD } \\
\hline \multicolumn{4}{|l|}{ Notes time of SD } \\
\hline \multicolumn{4}{|l|}{ Calls for help/nurses/anesthesia } \\
\hline \multicolumn{4}{|l|}{ Instructs McRoberts correctly } \\
\hline \multicolumn{4}{|l|}{ Instructs suprapubic pressure correctly } \\
\hline \multicolumn{4}{|l|}{ Applies gentle downward or axial traction } \\
\hline \multicolumn{4}{|l|}{$\begin{array}{l}\text { Performs (in no particular order) release } \\
\text { maneuvers: }\end{array}$} \\
\hline \multicolumn{4}{|l|}{ Rubin } \\
\hline \multicolumn{4}{|l|}{ Woods Screw } \\
\hline \multicolumn{4}{|l|}{ Posterior arm release } \\
\hline \multicolumn{4}{|l|}{ Zavanelli maneuver } \\
\hline \multicolumn{4}{|l|}{ Epesiotomy (if done) } \\
\hline \multicolumn{4}{|l|}{ Fracture of anterior clavicle } \\
\hline \multicolumn{4}{|l|}{ All fours maneuver (if applicable) } \\
\hline \multicolumn{4}{|l|}{ Notes time of delivery of body } \\
\hline \multicolumn{4}{|l|}{ Identifies which shoulder was anterior } \\
\hline \multicolumn{4}{|l|}{ Assesses baby status/arm movements } \\
\hline \multicolumn{4}{|l|}{$\begin{array}{l}\text { Conducts post delivery debriefing with nurse } \\
\text { team }\end{array}$} \\
\hline $\begin{array}{l}\text { Documents sD properly (written, dictated)- } \\
\text { estimated fetal weight/gentle downward/axial } \\
\text { traction/delivery of head/delivery of } \\
\text { body/maneuvers } \\
\text { attmepted/successful/personnel/neonatal } \\
\text { injuries/apgars/birth weight }\end{array}$ & & & \\
\hline
\end{tabular}

Figure 1 - Shoulder Dystocia Checklist

communication were communicated informally to participants during the simulation exercises through moderatorinitiated prompts to verbalize the thought process in which the participant was engaged. The moderator facilitated a debriefing session immediately following each scenario by asking the physician and nurse to discuss their thoughts about what went well during 
Student Name:

Date:

Instructor Name:

Stage 0

Describe:

A. Assessment

B. Medications/ procedures

C. Blood Bank/ other personnel needed

A. Assessment: Is the birth normal or increased amount of blood loss (postpartum hemorrhage)? Moderator teaching point: Consider the ways we calculate $E B L$

1. $<500 \mathrm{ml}$ Vaginal

B. Medications/ Procedures

2. Oxytocin 10 units IV or IM

3.___ Vigorous fundal massage

C. Blood bank/other personnel needed

4. ___ Type and screen in lab and admission hematocrit (done pre-delivery)

\section{Stage One}

Describe:
A. Assessment
B. Medications/ procedures
C. Blood Bank/ other personnel needed

A. Assessments: Ongoing Evaluation

5. ___ Quantification of blood loss based on actual mannequin bleeding and vital signs ( $>500 \mathrm{ml}$ vaginal)

6. Activate Obstetrical Massive Transfusion Protocol Moderator teaching point: confirm participant is familiar with the guidelines in hospital's protocol

B. Medications/procedures

7. Increase IV rate

8. Increase Oxytocin

9. Methergine $0.2 \mathrm{mg} \mathrm{IM}$ (if not hypertensive)

10. ___ Continue fundal massage

11. E__ Empty bladder using Foley catheter

12. ___ Keep patient warm with additional blankets and adjusting room temperature

13. Administer oxygen to maintain $\mathrm{O}_{2}$ Saturation $>95 \%$

14. _ Rule out retained products of conception

15. Rule out laceration(s)

16. Rule out hematoma

C. Blood Bank/other personnel needed

17. Type and cross 2 units packed red blood cells

18.___ Ask for help from additional clinicians - Anesthesia ___ Nursing ___ Attending Obstetrician___Laborist

\section{Stage Two}

Describe:
A. Assessment
B. Medications/ procedures
C. Blood Bank/other personnel needed

A. Assessments

19. ___ Ongoing assessment of bleeding based on actual mannequin bleeding and vital signs (1000 $\mathrm{ml}-1500 \mathrm{ml})$

Figure 2 - Postpartum Hemorrhage Checklist 


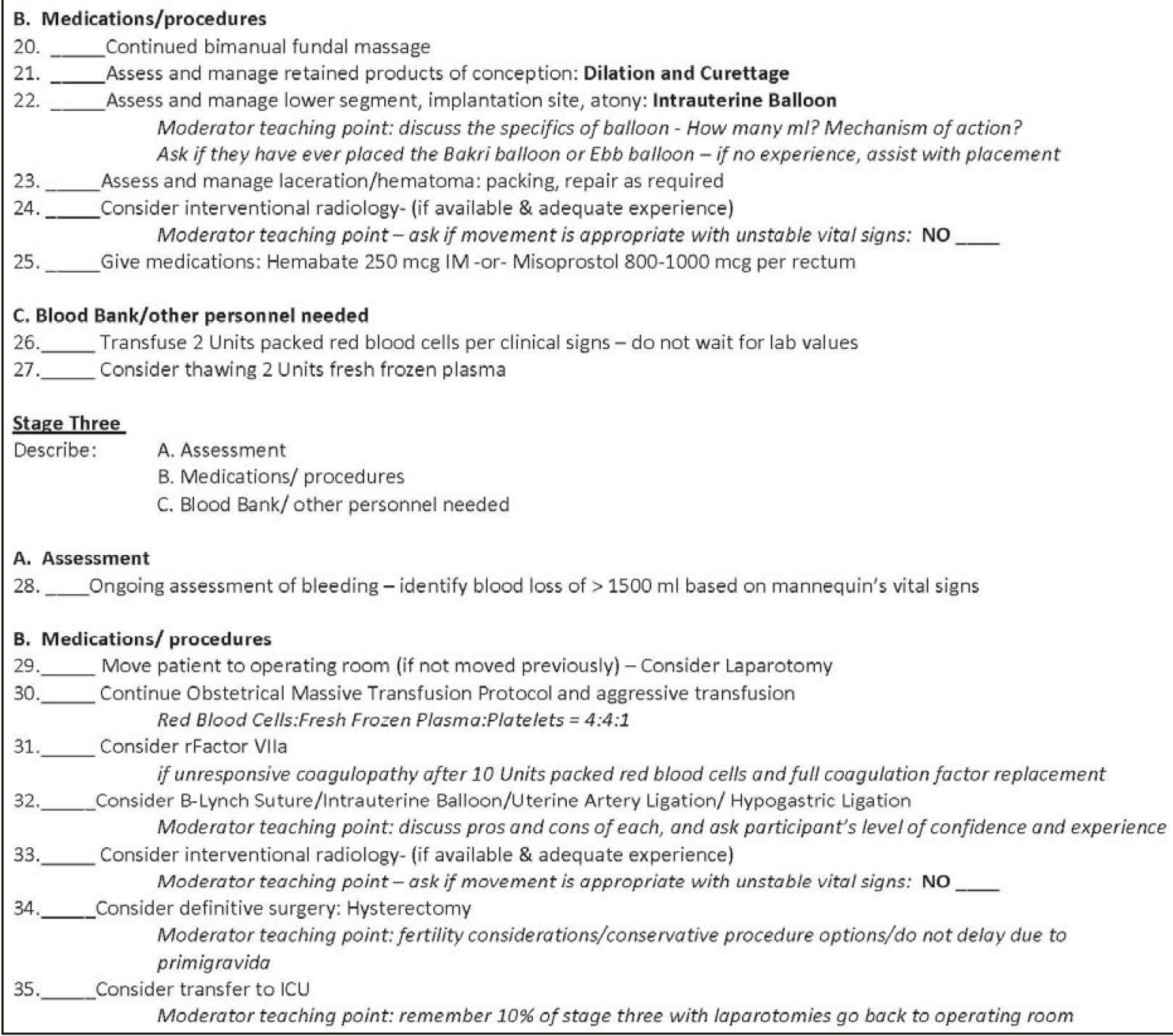

Figure 2 - Postpartum Hemorrhage Checklist (continued)

the scenario, areas for personal improvement, and any follow up items that needed to be addressed. Once the scenario debriefing ended, the moderator encouraged the participant and the nurse to share experiences with communication and debriefing from their clinical practice. This sharing opportunity led to open dialog about how this exercise might change practice behavior. The Faculty also discussed basic principles and how debriefing can be incorporated into practice.
Commercially available simulators were used for the hands-on simulation exercises. The Noelle S575, a highfidelity mannequin from Gaumard, was used for postpartum hemorrhage scenarios because of its ability to produce real-time vital signs and simulate hemorrhage with red-dyed water. The scenarios created by the Faculty were programmed into the Noelle user interface to run automatically. The PROMPT Birthing Simulator from Laerdal was used for shoulder dystocia scenarios because it allowed the moderator to control the 
position of the fetus and apply resistance to the participants' delivery attempts. Hands-on sessions were held in a dedicated obstetrical simulation classroom within the Labor and Delivery Department that had been established previously for the nursing CETT program. The hospital had also previously purchased the Noelle S575 for use with the CETT program. The PROMPT Birthing Simulator and other supplies were purchased through the CME Department.

Data were analyzed using Chi-square testing with a $p$ value of $<0.05$ felt to be significant.

\section{RESULTS}

71 out of 74 physicians required to participate in simulation training completed the Program described in this study. The three remaining physicians fulfilled the requirement through a simulation experience outside the scope of this paper. $91.9 \%$ of the required physicians completed the course between October 26, 2010 and the initial deadline of January 31, 2010. Following the deadline, there was a grace period through June 30, 2010 during which the remaining physicians could attend select sessions for a fee of $\$ 400$ to fulfill the requirement. After June 30, 2010, privileges would be revoked. The remaining $8.1 \%$ participated in the Program during the grace period.

Pre and post test data was collected from 71 respondents, and analyzed to gauge the effectiveness of the webbased module. The demographics of the participants are noted in Table 1 below. Results of the pre and post tests indicated an improvement in clinical knowledge surrounding management of shoulder dystocia and postpartum hemorrhage based on the web-based module. A summary of the results and analysis is noted in Tables 2 and 3 below.

\begin{tabular}{|l|l|l|l|l|}
\hline \multicolumn{5}{|l|}{ Table 1 Participant Demographics } \\
\hline Female & Male & $\begin{array}{l}\text { Highest Level of Training } \\
- \text { Residency }\end{array}$ & $\begin{array}{l}\text { Highest Level of Training - } \\
\text { Fellowship }\end{array}$ & $\begin{array}{l}\text { Average Years } \\
\text { Since Training }\end{array}$ \\
\hline 41 & 30 & 63 & 8 & 17 \\
\hline
\end{tabular}

Table 2 - Scores for shoulder dystocia

\begin{tabular}{|l|l|l|c|}
\hline & Pre-test & Post-test & Change \\
\hline Average score & $79.01 \%$ & $94.37 \%$ & $19.43 \% ; \mathrm{p}<0.05$ \\
\hline
\end{tabular}

Table 3 - Scores for postpartum hemorrhage

\begin{tabular}{|l|l|l|l|}
\hline & Pre-test & Post-test & Change \\
\hline Average score & $87.46 \%$ & $94.37 \%$ & $7.89 ; \mathrm{p}=\mathrm{NS}$ \\
\hline
\end{tabular}

To gauge the impact of the Program among the Department members, a follow up survey was sent to all participants three months after their hands-on sessions. The survey indicated satisfaction with and acceptance of simulation as a mechanism for training within our environment, with $20 \%$ of respondents indicating they had implemented a practice change in managing a shoulder dystocia or postpartum hemorrhage 
case that would not have been implemented prior to participating in the training; $85.2 \%$ of respondents stating they were likely to attend another $\mathrm{CME}$ activity involving simulation; and, $92.6 \%$ of respondents stating that compared to othereducational activities, simulation offered the best value for time spent.
Survey responses also indicate an overall positive change in perception of simulation training after completing the Program. Table 4 includes a summary of the responses to three month follow up questions surrounding participant experience.

\begin{tabular}{|l|}
\hline Table 4 - Response summary for questions $7-10$ on three month follow up survey \\
Question 7 of 10: How did your perception of simulation training change after taking the \\
course? \\
\hline Select Responses \\
\hline$\square$ does appear potentially helpful \\
\hline$\square$ was an excellent drill and not a pass/fail exam \\
\hline$\square$ didn't change \\
\hline$\square$ it was not as intimidating as it could have been \\
\hline$\square$ overall, it was an enjoyable process \\
\hline$\square$ I was glad that all the OBs had undergone this training \\
\hline$\square$ felt more confident in my knowledge of the management algorithm \\
\hline$\square$ I am less intimidated by a simulation training session \\
\hline$\square$ I was very upset that we had to do yet one more thing and I was very surprised how helpful it \\
was! \\
\hline$\square$ didn't change - I thought it was a good idea in the first place \\
\hline$\square$ great learning tool, instructors were so nice \\
\hline$\square$ improved - very pleasant experience. \\
\hline$\square$ I think it is very helpful and confidence building \\
\hline$\square$ it was a positive learning experience rather than a test \\
\hline$\square$ completely - I saw it as a good, nonthreatening help session very likely to make me perform \\
better in two of our worst emergencies \\
\hline$\square$ this was the first simulation training course I had taken, and I thought it was very helpful - a \\
great review and learned a few new things as well. \\
\hline$\square$ better than I expected \\
\hline$\square$ it is now less daunting \\
\hline$\square$ before, I thought it would just be a waste of time, but after taking the course, I thought the \\
hands on component was very valuable, as well as talking through different scenarios
\end{tabular}




\begin{tabular}{|l|}
\hline$\square$ faculty was great in outlining the Shoulder Dystocia management and gave me some new \\
tools to use \\
\hline $\begin{array}{l}\text { written handout with the algorithm plainly noted and use of the same algorithms in L\&D on } \\
\text { large poster boards }\end{array}$ \\
\hline$\square$ wonderful \\
\hline$\square$ liked it all - faculty were great and simulations were excellent \\
\hline$\square$ I really thought it was super \\
\hline$\square$ interactive learning in a non-threatening manner \\
\hline$\square$ General attitude of helpfulness in the instructors - no sense of judgment or condescension \\
\hline$\square$ Interactive aspect \\
\hline$\square$ well-organized \\
\hline$\square$ I thought the on-line piece was great \\
\hline$\square$ small groups kept it informal, and able to learn a lot; short and to the point - well organized \\
and made good use of my time \\
\hline$\square$ time-consuming \\
\hline$\square$ I liked that it wasn't confrontational or intimidating even though the proctors were gods in their \\
fields \\
\hline$\square$ I don't appreciate mandatory involvement \\
\hline$\square$ low key, validated knowledge and confidence \\
\hline$\square$ overall very good and a good review \\
\hline
\end{tabular}

\section{Question 9 of 10: In comparison to other CME formats, how likely would you be to attend another simulation-based CME activity?}

Answer Options

Very Unlikely

Somewhat Unlikely

Somewhat Likely

Very Likely

Response Percent

$11.1 \%$

$3.7 \%$

$29.6 \%$

$55.6 \%$

Comments

$\checkmark$ look forward to it

$\square$ I don't have time or money to block patient times to do "mandatory" activities like this - it costs me money and I resent the intrusion into my schedules - however, I actually liked the program - that was a surprise

$\square$ it depends on who the proctors are

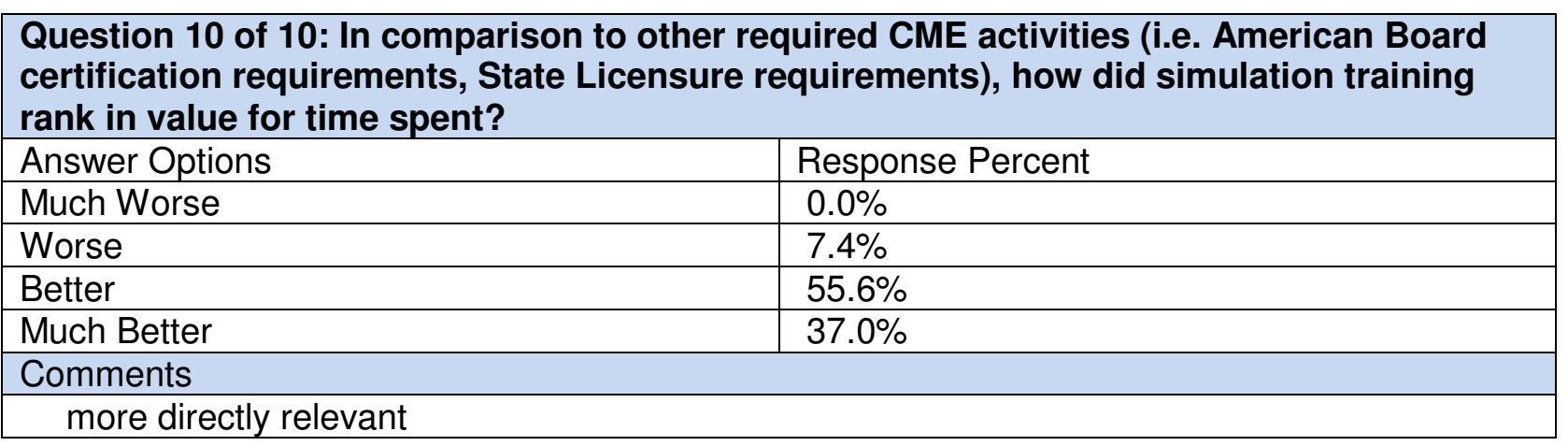




\section{DISCUSSION}

Some of the leading causes of significant morbidity and mortality involve cases related to obstetrical hemorrhage and shoulder dystocia.5,6 Through the implementation of a required obstetrical simulation training program focusing on the clinical management of these emergencies, hospital leadership and Program Faculty intended to reduce the risk of morbidity and mortality for their patients. While the data to support such an impact is outside the scope of this study, our experience does suggest that it is possible to successfully implement simulation-based education for experienced, attending obstetrical physicians at a large, private, urban hospital.

Daniels et al demonstrated that while didactic and simulation trained groups performed equally on written test scores, simulation trained teams had superior performance in actual events. ${ }^{2}$ With a program established, and data suggesting a high rate of satisfaction in a diverse provider group, the hospital and Program Faculty have committed to sustained support of the Program in an effort to improve performance in actual events. Further studies are needed to assess the long-term efficacy of this program related to clinical performance and outcomes.

One of the strengths of this study is that the self-learning section of the program involved a pre-test without study or presentation of the material. This allowed for true assessment of the learners' clinical knowledge prior to proceeding to the simulation experience, and allowed the Faculty to address any deficiencies during the hands-on session. Another strength of this study is the years in clinical practice for our learners. In most studies where simulation has been noted to be beneficial, the learners are residents with limited years in clinical practice.

A weakness of this study is only $42.3 \%$ of participants completed the three month follow up survey. This lack of follow up with the other learners may have provided selection bias as the respondents were more excited about the program than those who chose not to respond.

\section{References}

1. Andreatta PB, Bullough AS, Marzano D. Simulation and team training. Clin Obstet Gynecol. 2010 Sep;53(3):53244. Review. PubMed PMID: 20661038. http://dx.doi.org/10.1097/GRF.0b013e31 81 ec1a48

2. Daniels K, Arafeh J, Clark A, Waller S, Druzin M, Chueh J. Prospective randomized trial of simulation versus didactic teaching for obstetrical emergencies. Simul Healthc. 2010 Feb;5(1):40-5. PubMed PMID: 20383090.

http://dx.doi.org/10.1097/SIH.0b013e31 $81 \mathrm{~b} 65 \mathrm{f} 22$

3. Centers for Disease Control and Prevention (CDC). Maternal mortalityUnited States, 1982-1996. MMWR Morb Mortal Wkly Rep. 1998 Sep 4;47(34):705-7. PubMed PMID: 9746397.

4. Joint Commission on Accreditation of Healthcare Organizations, USA.Preventing maternal death. Sentinel Event Alert. 2010 Jan 26;(44):1-4. PubMed PMID: 20183946.http://www.jointcommission.or $\mathrm{g} /$ sentinel event alert issue 44 preven ting maternal death/ (Accessed January 2012) 
5. Jacobs A. Causes and treatment of postpartum hemorrhage. UpToDate. 2010 Jan 18;version 18.1. http://www.uptodate.com/online/content/ topic.do?topicKey=postpart/4483\&view= print (Accessed July 2010)

6. Deering $\mathrm{SH}$, Weeks L, Benedetti $\mathrm{T}$. Evaluation of force applied during deliveries complicated by shoulder dystocia using simulation. Am J Obstet Gynecol. 2011 Mar;204(3):234.e1-5. Epub 2010 Nov 20. PubMed PMID: 21093848.

http://dx.doi.org/10.1016/j.ajog.2010.10. 904 